\title{
Computed tomography in aneurysmal subarachnoid haemorrhage
}

\author{
B A BELL, B E KENDALL, AND LINDSAY SYMON
}

From the Gough Cooper Department of Neurological Surgery and Lysholm Department of Neuroradiology, The National Hospital, Queen Square, London

SUMMARY The initial CT scans of 76 patients with aneurysmal subarachnoid haemorrhage were reviewed, and the amount of blood visible in the basal CSF cisterns was quantified. The outcome of surgery was found to correlate significantly with the quantity of blood seen on the scan, as did the pre-operative grade of the patient, a history of pre-existing hypertension, and the presence of angiographic vasospasm.

Computed tomography has become established as the initial investigation of a patient who has recently sustained a subarachnoid haemorrhage (SAH). The demonstration of subarachnoid blood confirms the diagnosis, and the site of the source of haemorrhage may be predicted prior to angiography. ${ }^{1}$ Large aneurysms are visible on plain scans, and with attention to detail, including overlapping sections, it is possible to detect up to $76 \%$ of anterior and middle cerebral aneurysms after contrast enhancement. ${ }^{2}$ Areas of low attenuation may indicate cerebral oedema or ischaemia secondary to vasospasm induced by the haemorrhage, and ventricular size is shown so that any hydrocephalus can be detected. Intracerebral extension of the haemorrhage may be seen, and when an arteriovenous malformation or a tumour has caused the bleeding, it will be visible on the scan.

With the exception of a variable amount of blood in the subarachnoid space, the majority of scans in patients who have recently bled from an aneurysm are normal. Such a scan is of limited use to the clinician assessing the patient, and so we have tried to correlate the blood visible on the scan with various clinical features in the patients.

\section{Patients and methods}

All patients with aneurysmal SAH admitted for surgery under the care of one surgeon (LS) during

Address for reprint requests: Professor Lindsay Symon, Gough Cooper Department of Neurological Surgery, The National Hospital, Queen Square, London WCIN 3BG.

Accepted 21 February 1980 the period 1976-1979 were reviewed. From a total of 97 patients, 76 had a CT scan performed as the initial investigation within 15 days of their bleed, and it was this group that was studied further. The initial CT scans were reviewed blind by one neuroradiologist (BEK), and according to the amount of blood visible in the basal cisterns on the photographic record of the scan, the patients were classified into three groups.

Where the attenuation in the basal cisterns was less than that of the surrounding brain, the scan was classified as low density. Where the basal cisterns had an attenuation similar to that of brain, the scan was classified as isodense, and where the attenuation exceeded that of brain, the scan was classified as high density. The timing of the three groups of scans in relation to the bleed is shown in fig 1 , the majority of patients being scanned within a week of SAH. Fourteen patients bled twice prior to surgery, and three bled on three occasions. In these patients the scan was taken following the last bleed prior to surgery.

All patients were given a clinical grading pre-operatively on the five point scale of Hunt and Hess, ${ }^{3}$ and the average grade of the patients in each scan group was computed. Evidence of pre-existing hypertension was sought in each patient, by a study of their previous medical history, drug therapy prior to the ictus, and the appearance of the vessels in their fundi. This information was available in 68 patients, and the hypertensive history was correlated with the scan appearance. All the patients underwent angiography prior to surgery, and the detection 


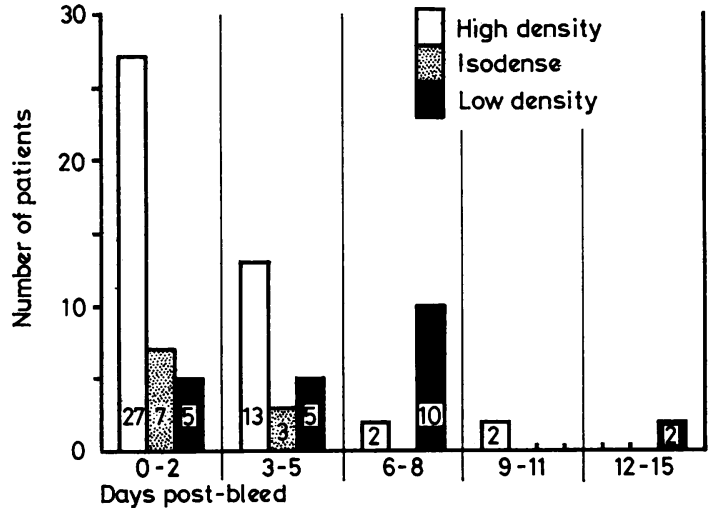

Fig 1 Timing of CT scan following the bleed

of spasm by the radiologist reviewing the initial angiograms, performed within 15 days of the SAH, was noted. The proportion of patients in each scan category showing angiographic spasm was calculated, as was the timing of angiography in relation to the bleed.

An operation was performed on every patient by a single surgeon (LS), to exclude from the circulation the aneurysm that had bled. The outcome of this surgery, at two months from the operation date, was then compared with the pre-operative scan category of the patient. A good outcome represented a patient back at work or able to manage her home again, and a poor outcome included those patients who died and those requiring continuing care at home or in an institution. Statistical comparisons were performed using the chi-square test, with Yate's correction for continuity.

\section{Results}

The age and sex distribution of the 76 patients is shown in table 1 , and the site of their aneurysms in table 2 . They represent a cross section of the patients admitted to this hospital, and their distribution does not differ greatly from that found in larger series. ${ }^{4}$ The pre-operative grade of the patients was found to correlate with the amount of blood on their scans (table 3 ), the average grade of patients with low density scans being just over two, and of those with high density scans the average grade was almost three. Evidence of pre-existing hypertension was found more frequently in those patients with more blood on the scan, and this finding was highly significant when patients with high and low density scans are compared (table 3). Preoperative angiographic spasm was more prevalent
Table 1 Age and sex distribution of patients

\begin{tabular}{lllllll}
\hline \multicolumn{7}{c}{ Age (yr) } \\
\cline { 2 - 7 } & $10-19$ & $20-29$ & $30-39$ & $40-49$ & $50-59$ & $60-69$ \\
\hline Male & 1 & 1 & 3 & 4 & 10 & 7 \\
Female & & 4 & 6 & 9 & 24 & 7 \\
\hline
\end{tabular}

Table 2 Aneurysm site

\begin{tabular}{llll}
\hline $\begin{array}{l}\text { Anterior } \\
\text { communicating } \\
33\end{array}$ & $\begin{array}{l}\text { Posterior } \\
\text { communicating } \\
17\end{array}$ & $\begin{array}{l}\text { Middle } \\
\text { cerebral } \\
11\end{array}$ & $\begin{array}{l}\text { Terminal } \\
\text { carotid } \\
5\end{array}$ \\
$\begin{array}{l}\text { Pericallosal } \\
4\end{array}$ & $\begin{array}{l}\text { Ophthalmic } \\
1\end{array}$ & $\begin{array}{l}\text { Basilar } \\
1\end{array}$ & $\begin{array}{l}\text { PICA } \\
1\end{array}$ \\
& \multicolumn{2}{c}{$\begin{array}{l}\text { Multiple } \\
\end{array}$} \\
\hline
\end{tabular}

Table 3 Pre-operative grades and hypertensive history

\begin{tabular}{lccc}
\hline & \multicolumn{3}{l}{ Scan density grading } \\
\cline { 2 - 4 } & High & Isodense & Low \\
\hline $\begin{array}{l}\text { Average } \\
\text { Pre-operative }\end{array}$ & 2.82 & 2.40 & 2.27 mean \\
$\begin{array}{l}\text { grade } \\
\text { hypertensive }\end{array}$ & \pm 0.95 & \pm 1.07 & $\pm 0.77 \mathrm{SD}$ \\
\hline Sistory & $38 \% *$ & $30 \%$ & $26 \% *$ \\
\hline
\end{tabular}

"Significant difference $p<0.001$.

Table 4 Angiographic spasm

\begin{tabular}{lccc}
\hline & \multicolumn{3}{l}{ Scan density grading } \\
\cline { 2 - 4 } & High & Isodense & Low \\
\hline $\begin{array}{l}\text { Spasm on } \\
\text { pre-operative } \\
\text { angiogram }\end{array}$ & $50 \%$ & $38 \%$ & $29 \%$ \\
$\begin{array}{l}\text { Timing of } \\
\begin{array}{l}\text { angiography } \\
\text { in days } \\
\text { post-bleed }\end{array}\end{array}$ & 3.8 & 4.4 & 3.4 mean \\
\hline
\end{tabular}

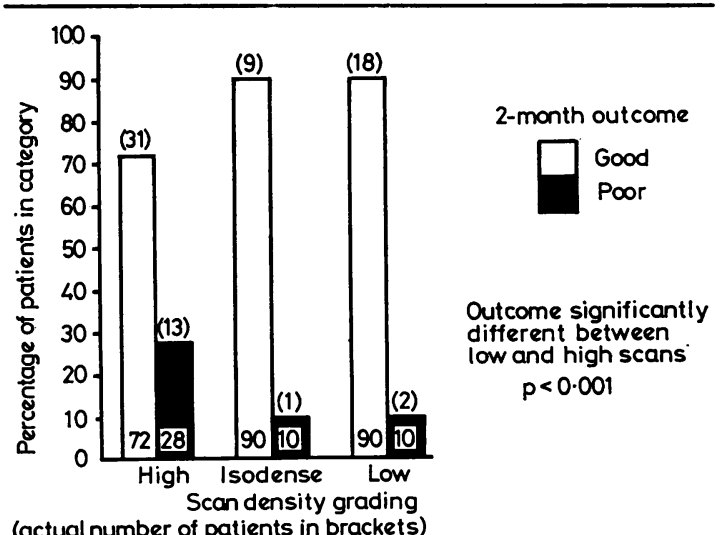

Fig 2 Outcome 2 months following surgery and CT scan grading 
in patients with high density scans, the timing of angiography being similar for patients in each scan category (table 4).

The correlation between the outcome of sungery and the amount of blood on the preoperative scan was highly significant (fig 2). Patients with high density scans were more likely to do badly by a factor of 3.8 times than patients with low density scans.

\section{Discussion}

Our findings show that the amount of blood in the basal cisterns, shown on an acute CT scan following aneurysmal SAH, can be a very useful factor in predicting the outcome of subsequent surgery. The suggestion that marked subarachnoid and intraventricular blood correlates with a poor neurological status ${ }^{5}$ is confirmed in that the average grade of patients with a large amount of blood on the basal scan sections is higher than the grade of those with a small amount of blood.

Ideally the acute CT scan should be taken immediately after the bleed, and patients who rebleed should be re-scanned soon afterwards. In practice the first CT scan is taken at a variable interval following the ictus, however such scans remain useful, as high density cisterns were still noted nine days after the bleed in two of our patients. The five day period for the disappearance of blood from the cisterns, taken by previous authors ${ }^{7} 7$ is obviously exceeded by some of our cases. The detection of blood up to three weeks following the bleed, as suggested by some workers, ${ }^{8}$ cannot be confirmed from our cases, however the estimate of six to ten days put forward by Scotti and his colleagues, ${ }^{9}$ would fit with our data, the two patients scanned beyond .12 days from the bleed both having low density cisterns.

Our results also suggest that hypertensive patients are more likely to have a large bleed from an aneurysm than normotensive patients, and thus to fare worse subsequently. Vascular spasm detected at angiography within 15 days of the bleed also correlates with high density in the basal cisterns during the same period after bleeding.
Clearly the early scanning of patients admitted with a SAH is very worth while, and as well as confirming the diagnosis and showing complications of the bleed, the initial scan can now be used to help in the determination of the patient's prognosis.

BAB was funded by the Medical Research Council.

\section{References}

1 Hayward RD, O'Reilly GVA. Intracerebral haemorrhage. Accuracy of computerised transverse axial scanning in predicting the underlying aetiology. Lancet 1976; 1:1-4.

2 Ghoshhajra K, Scotti L, Marasco J, BaghaiNaiini P. CT detection of intracranial aneurysms in subarachnoid haemorrhage. Am J Roentgenol 1979; 132:613-6.

3 Hunt WE, Hess RM. Surgical risk as related to time of intervention in the repair of intracranial aneurysms. J Neurosurg 1968; 28:14-9.

4 Locksley HB. Report of the co-operative study of intracranial aneurysms and subarachnoid haemorrhage, Section V, Part I: Natural history of subarachnoid haemorrhage, intracranial aneurysms and arterio-venous malformations. Based on 6368 cases in the co-operative study. J Neurosurg 1966; 25:219-39.

5 Davis KR, New PFJ, Ojemann RG, Crowell RM, Morawetz RB, Roberson GH. Computed tomographic evaluation of haemorrhage secondary to intracranial aneurysm. Am J Roentgenol 1976; 127:143-53.

6 Weisberg LA. Computed tomography in aneurysmal subarachnoid haemorrhage. Neurology 1979; 29:802-8.

7 Liliequist B, Lindqvist $M$, Valdimarsson $E$. Computed tomography and subarachnoid haemorrhage. Neuroradiology 1977; 14:21-6.

8 Isu T, Vemura K, Goto K, Ishi K. Computed tomographic findings in intracranial haemorrhage due to ruptured intracranial aneurysm. Rinsho Hohasen 1978; 23:701-9.

9 Scotti G, Ethier R, Melancon D, Terbrugge K, Tchang S. Computed tomography in the evaluation of intracranial aneurysms and subarachnoid haemorrhage. Radiology 1977; 123:85-90. 